\title{
Diagnosis and treatment of digoxin toxicity
}

\author{
Gregory Y.H. Lip, Malcolm J. Metcalfe and Francis G. Dunn
}

Department of Cardiology, Stobhill General Hospital, Glasgow G21 3UW, UK

\section{Introduction}

Cardiac glycosides are unusual in having a narrow therapeutic range, which is idiosyncratic to the individual. In view of this it is perhaps not surprising that toxicity is a common occurrence, being reported in up to $35 \%$ of digitalized patients. ${ }^{1}$

There are several mechanisms which can lead to this problem. Firstly, digoxin is excreted mainly by the kidneys, and therefore, any impairment of renal function may lead to higher than expected plasma concentrations. Congestive cardiac failure, renal failure and advanced age can also cause toxicity by reducing the volume of distribution of the drug. Concomitant electrolyte imbalance, notably hypokalaemia, hypomagnesaemia and hypercalcaemia can potentiate digoxin toxicity. Approximately $30 \%$ of digoxin is plasma protein bound and thus certain other drugs such as amiodarone and calcium antagonists can lead to higher than expected plasma concentrations. Lastly, several clinical conditions such as hypothyroidism, chronic lung disease and cardiac amyloid are associated with an abnormally high myocardial sensitivity to digoxin. Despite all of this, however, there is often still no clear relationship between these factors and manifest toxicity.

\section{Diagnosis of toxicity}

\section{Clinical features}

Features of cardiac glycoside toxicity are usually non-specific and can be conveniently divided into cardiac and non-cardiac effects. ${ }^{2,3}$ Non-cardiac symptoms such as anorexia, nausea, vomiting, lethargy, headaches, confusion and more rarely visual disturbances are the most frequent presenting features. With increasing toxicity, the more serious cardiac features become inevitable, although occasionally they can be the presenting problem. Almost any permutation of heart block, brady- and tachydysrhythmias are possible. ${ }^{2}$ It is

Correspondence: G.Y.H. Lip, M.R.C.P.

Accepted: 4 December 1992 important to emphasize that the clinical diagnosis of toxicity is of fundamental importance and should not be discarded because of 'normal' plasma digoxin concentrations.

\section{Use of plasma concentration measurements}

In an attempt to improve digoxin therapy, it is frequently advocated that the plasma digoxin concentration should be measured. Trough plasma concentrations below $0.8 \mathrm{ng} / \mathrm{ml}(1.0 \mathrm{nmol} / \mathrm{l})$ are considered sub-therapeutic and levels greater than $2.0 \mathrm{ng} / \mathrm{ml}(2.56 \mathrm{nmol} / \mathrm{l})$ toxic. Unfortunately, there is a marked overlap of measured plasma levels between groups of patients with and without evidence of toxicity. ${ }^{3,4}$ For example, one patient may exhibit evidence of toxicity at a measured plasma drug level of only $0.8 \mathrm{ng} / \mathrm{ml}$, whilst another may be symptom free at a level of $3.0 \mathrm{ng} / \mathrm{ml}$.

It can thus be seen that plasma level concentration estimation is only of limited clinical value. Plasma level measurements may be useful to confirm clinical signs of toxicity or to see whether or not there is any scope for reducing the dose and still achieving a therapeutic effect. Plasma levels are also useful to monitor compliance, to allow adjustment of dosage in the presence of certain concomitant therapy and (in certain circumstances) to monitor treatment of overdosage. There is, nevertheless, no place for performing 'routine' drug level assessments in clinical practice.

\section{General principles of management}

When a patient is diagnosed as suffering from digoxin toxicity, the initial step is to assess the severity of the problems. The reason for the development of toxicity should always be thoroughly sought: for example, use of an inappropriate high dose, the addition of concomitant medication or the development of a reduced volume of distribution arising owing, for example, to progression of heart failure or development of renal impairment. The question of either accidental or deliberate overdosage should also be considered. 
If the evidence of toxicity is relatively minor with, for example, symptoms of nausea, withdrawal of the drug is often the only specific treatment required. More serious evidence of toxicity, particularly with cardiac involvement, requires admission to hospital.

If there is no evidence of serious cardiac problems, such as heart block or significant dysrhythmias, then following the withdrawal of the drug and the correction of electrolyte imbalance, symptomatic measures will usually suffice. The presence of major dysrhythmias is clearly potentially lifethreatening and carries a high mortality. In these circumstances, a rapid and more aggressive management stratagem must therefore be followed, ideally within the coronary care unit with experienced staff available.

Immediate management centres around treatment of heart block with atropine $(2-3 \mathrm{mg})$ and temporary pacing. Malignant ventricular dysrhythmia should be treated with beta-blockers, lignocaine or phenytoin. Phenytoin (100 mg intravenously, repeated after 5 minutes if required) is a useful antidysrhythmic as it opposes digitalis binding and may improve atrioventricular conduction by its anticholinergic properties. ${ }^{1}$ Beta-adrenoceptor blocking agents can terminate glycosideinduced ventricular dysrhythmias but are more likely to lead to heart block. ${ }^{5-7}$ Therefore an ultra-short acting intravenous beta-blocker preparation such as esmolol (half-life, $t_{4}=9$ minutes) may be useful in these circumstances as its effects may be rapidly reversed. ${ }^{8}$ Correction of hypokalaemia is important, generally requiring intravenous supplementation of no more than $20 \mathrm{mmol} / \mathrm{h}$ of potassium, to reduce digitalis binding to $\mathrm{Na} / \mathrm{K}$ ATPase. ${ }^{1,9}$ More rapid infusion of potassium may lead to asystole and concomitant infusion of dextrose may aggravate any hypokalaemia. $^{5}$

Cardioversion should be avoided wherever possible, due to the risk of precipitating asystole, and when necessary should be attempted using the lowest energy possible. Elimination of the cardiac glycoside should then be performed as expeditiously as possible using digoxin-specific antibody fragments.

In accidental or deliberate overdosage, general principles of treatment remain the same. If the drug has been ingested within 4 hours the patient should undergo immediate gastric lavage leaving $100 \mathrm{~g}$ of activated charcoal within the stomach. If ingested after 4 hours then the patient should be treated only with activated charcoal. There is evidence that this therapy is as effective as ipecacuanha-induced vomiting in preventing drug absorption. ${ }^{10}$

\section{Specific aspects of management}

\section{Activated charcoal}

One of the most effective agents for the treatment $\stackrel{.}{.}$ of digoxin toxicity is activated charcoal. This agent $\overrightarrow{\vec{F}}$ is especially useful for patients who have taken a $\stackrel{?}{?}$ recent overdosage of digoxin, for patients without serious evidence of toxicity but otherwise sympto- $\frac{\bar{\sigma}}{\bar{N}}$ matic, or in situations of serious toxicity when $\overrightarrow{\widetilde{\sigma}}$ digoxin-specific antibodies are unavailable. In $\cong$ order to achieve an adequate therapeutic response, $ळ$ multiple oral doses of activated charcoal are often $\vec{\circ}$ required to maintain an effective concentration gradient. A suggested regimen is a loading dose of $\vec{\omega}$ $50-100 \mathrm{~g}$, followed by either $10 \mathrm{~g}$ hourly, $10-20 \mathrm{~g}$ 응 2 hourly or $40 \mathrm{~g} 4$ hourly. ${ }^{10-12}$

Activated charcoal has been shown to increase the clearance of digoxin by two mechanisms. ${ }^{11,13}$ of Firstly, and of greatest importance, is its effect in $\stackrel{\infty}{\rightarrow}$ moderating 'gastrointestinal dialysis' using the $\overrightarrow{\dot{\omega}}$ gastrointestinal wall as a dialysis membrane. ${ }^{11,12} \omega_{\mathcal{U}}$ Secondly, it interferes with the enterohepatic cir- 0 culation of digoxin by binding to the drug in the $\stackrel{?}{\longrightarrow}$ intestinal lumen, resulting in increased elimination $\vec{z}$ of the recycled drug. ${ }^{12}$ Other binding agents such as colestipol and cholestyramine have also been shown to be effective. ${ }^{11,13}$ In contrast, haemo $\notin$ dialysis and haemoperfusion are clinically ineffe tive. ${ }^{14,15}$

The potential benefits of such an effective, simp and inexpensive mode of treatment have to be weighed, however, against any resultant morbidity. The major problems are unpalatability of the activated charcoal and the risk of aspiration in $\overrightarrow{\vec{O}}$ patients who may well be experiencing severe $\frac{}{3}$ nausea and vomiting. The treatment of these latter symptoms also poses problems, as the majority of antiemetic agents have concomitant anticholinergic properties, decreasing gastrointestinal motility and consequently the concentration gradient across the bowel. If the patient is in a state of shock then reduced splanchnic blood flow will also lead to reduced gastrointestinal motility.

\section{Digoxin-specific antibody fragments}

Digoxin-specific fab antibody fragments (Digibind, Wellcome) are possibly the most effective treatment available. However, this therapy is expensive and therefore should be reserved for treatment of serious toxicity, especially in the presence of cardiac dysrhythmias.

These antibodies have a high affinity and specificity for cardiac glycosides and have been shown to reverse digoxin toxicity and reduce the risk of death. ${ }^{16-18}$ In several large studies, approximately $80 \%$ of patients had complete resolution of all evidence of toxicity, $10 \%$ improved whilst $10 \%$ 
showed no response. ${ }^{16,17}$ They appear effective for all age groups and also in patients with poor renal reserve (despite eventual renal elimination). ${ }^{19}$

As with all foreign proteins, anaphylaxis, serum sickness or febrile reactions are a source of concern, especially with repeated administration. These reactions appear uncommon, ${ }^{2,16,17}$ for example, in a study of 717 adults where only six patients $(0.8 \%)$ exhibited any evidence of allergic response. ${ }^{20}$ Similarly to streptokinase therapy, repeated administration may possibly be less effective or more hazardous, but no evidence with regard to this matter is currently available.

The dose to be administered is calculated on the basis of the drug 'load', using the plasma concentration and body weight. ${ }^{2,21}$ The approximate dose of fab is 60 times the 'load', as the approximate molecular weight ratio of fab and digoxin is $60 .^{21}$ Generally improvement in signs and symptoms usually occurs within 30 minutes, with complete resolution of evidence of toxicity within 3-4 hours. ${ }^{2}$ Few adverse effects have been reported with the use of this agent. Nevertheless, theoretically, patients previously dependent upon the inotropic effects of digoxin could develop heart failure and hypokalaemia could result within $1-5$ hours, owing to intracellular shifts of potassium, as the effects of digoxin are reversed. ${ }^{2}$

Patients who require redigitalization must wait for the complexes to be eliminated from the body by the kidneys, this taking 2-3 days with normal renal function. ${ }^{2,22}$ Unfortunately, fab fragments interfere with both fluorescence excitation transfer immunoassays and radioimmunoassays for digoxin. This means that serum drug levels cannot be monitored until the drug-antibody complexes are cleared from the circulation. ${ }^{22-24}$

\section{Conclusion}

Digoxin toxicity is a common occurrence but for the majority of patients the problem is mild and effectively managed by symptomatic treatment and a reduction in dosage. Where symptoms and signs are more profound, but without any evidence of serious cardiac toxicity, then regular administration of oral activated charcoal is well worth considering. Development of serious toxicity with cardiac involvement requires prompt use of digoxin-specific fab fragments, which can be life saving.

\section{References}

1. Hayward, R. Digitalis: the present position. In: Hamer, J. (ed.) Drugs for Heart Disease, 2nd ed. Chapman and Hall, London, 1987, pp. 145-193.

2. Stolshek, B.S., Osterhout, S.K. \& Dunham, G. The role of digoxin-specific antibodies in the treatment of digitalis poisoning. Med Toxicol 1988, 3: 167-171.

3. Bayer, M.J. Recognition and management of digitalis intoxication: implications for emergency medicine. Am J Emerg Med 1991, 9 (2 Suppl 1): 29-32.

4. Selzer, A. Role of serum digoxin assay in patient management. J Am Coll Cardiol 1985, 5: 106A-110A.

5. Smith, T.W., Braunwald, E. \& Kelly, R.A. The management of heart failure. In: Braunwald, E. (ed.) Heart Disease: A Textbook of Cardiovascular Medicine, 4 th ed. W.B. Saunders, Philadelphia, 1992, pp. 464-519.

6. George, C.F. Digitalis intoxications: a new approach to an old problem. $\mathrm{Br} \mathrm{Med} J$ 1983, 286: 1533-1534.

7. Gibson, D. \& Sowton, E. The use of beta-adrenergic receptor blocking drugs in dysrhythmias. Prog Cardiovasc Dis 1969, 12: $16-39$.

8. Benfield, P. \& Sorkin, E.M. Esmolol. A preliminary review of its pharmacodynamic and pharmacokinetic properties, and therapeutic efficacy. Drugs 1987, 33: 392-412.

9. Steiness, E. \& Olesen, K.H. Cardiac arrhythmias induced by hypokalaemia and potassium loss during maintenance digoxin therapy. Br Heart J 1976, 38: 167-172.

10. Watson, W.A. Factors influencing the clinical efficacy of activated charcoal. Drug Intell Clin Pharm 1987, 21: 160-166.

11. Levy, G. Gastrointestinal clearance of drugs with activated charcoal. N Engl J Med 1982, 307: 676-678.

12. Lalonde, R.L., Deshpande, R., Hamilton, P.P., McLean, W.M. \& Greenway, D.C. Acceleration of digoxin clearance by activated charcoal. Clin Pharmacol Ther 1985, 37: 367-371.

13. Pond, S., Jacobs, M., Marks, J., Garner, J., Goldschlager, N. \& Hansen, D. Treatment of digitoxin overdose with oral activated charcoal. Lancet 1981, ii: 1177-1178.

14. Slattery, J.T. \& Koup, J.R. Hemoperfusion in the management of digoxin toxicity: is it warranted? Clin Pharmacokinet 1979, 4: 395-399.

15. Warren, S.E. \& Fanestil, D.D. Digoxin overdose: limitations of hemoperfusion and hemodialysis. JAMA 1979, 242: $2100-2101$.

16. Smith, T.W. Review of clinical experience with digoxin immune Fab (ovine). Am J Emerg Med 1991, 9 (2 Suppl 1): $1-6$.

17. Antman, E.M., Wenger, T.L., Butler, V.P., Haber, E. \& Smith, T.W. Treatment of 150 cases of life-threatening digitalis intoxication with digoxin-specific Fab antibody fragments. Final report of a multicenter study. Circulation 1990, 81: $1744-1752$.

18. Smith, T.W., Butler, V.P., Haber, E. et al. Treatment of life-threatening digitalis intoxication with digoxin-specific Fab antibody fragments. Experience in 26 cases. $N$ Engl $J$ Med 1982, 307: 1357-1362.

19. Wenger, T.L. Experience with digoxin immune Fab(ovine) in patients with renal impairment. Am J Emerg Med 1991, 9 (2 Suppl 1): 21-23.

20. Hickey, A.R., Wenger, T.L., Carpenter, V.P. et al. Digoxin immune Fab therapy in the management of digitalis intoxication: safety and efficacy results of an observational surveillance study. J Am Coll Cardiol 1991, 17: 590-598.

21. Digibind Data Sheet. Wellcome Medical Division, The Wellcome Foundation Ltd, UK.

22. Smith, T.W., Haber, E., Yeatman, L. \& Butler, V.P. Reversal of advanced digoxin intoxication with Fab fragments of digoxin specific antibody. $N$ Engl J Med 1976, 294: 797-800.

23. Gibb, I, Adams, P.C., Parnham, A.J. \& Jennings, K. Plasma digoxin: assay anomalies in Fab-treated patients. Br J Clin Pharmacol 1983, 16: 445-447.

24. Natowicz, M. \& Shaw, L. Digoxin assay anomalies due to digoxin-specific Fab immunotherapy. Drug Intell Clin Pharm 1991, 25: 739-741. 